\title{
Pedigrees with Diabetes Insipidus, Diabetes Mellitus, and Optic Atrophy*
}

\author{
J. H. SUNDER, T. S. DANOWSKI, F. M. KENNY, R. C. KHURANA, A. SUN, \\ S. NOLAN, and T. STEPHAN \\ From the Departments of Medicine and Pediatrics of the University of Pittsburgh and the Magee-Womens, \\ Children's and Shadyside Hospitals, Pittsburgh, Pennsylvania, USA
}

This report adds 4 members in a kindred with diabetes insipidus, diabetes mellitus, and optic atrophy to the published descriptions (DeLawter, 1949; Fraccaro and Gastaldi, 1952; Casa, 1955; Raiti, Plotkin, and Newns, 1963; Bretz et al, 1970; Ikkos et al, 1970) of the occurrences of all of these disorders within a single pedigree. In each of the families identified in the literature and in the present family all 3 manifestations were observed, though not necessarily in the same individual. The assembled data permit speculation concerning possibilities that the diabetes insipidus, diabetes mellitus, and optic atrophy in such a kindred represent manifestations of a single genetic trait.

\section{Case Reports}

Case 1. This 21-year-old male was found to have diabetes mellitus at the age of 10 years following polyuria, polydipsia, and polyphagia. Therapy with an anti-diabetic diet and insulin was instituted and continued to the present. $\mathrm{He}$ is now taking 70 units of Lente insulin. On this regimen, he has had one episode of ketoacidosis. At the age of 11, blurring of vision appeared and bilateral primary optic atrophy was discovered. Also at age 11, a diagnosis of diabetes insipidus was made following an increase in urine volume up to $81 /$ dy. A Hickey-Hare test (Hickey and Hare, 1944) did not reduce the volume nor raise the specific gravity of urine. Fluid deprivation overnight failed to increase urine osmolarity above that of serum. Vasopressin injections, 20 units every 2 days, decreased the urine volume to $21 / \mathrm{dy}$. During that year, the patient's intellectual capacity appeared to decrease. $X$-rays of the skull were negative. EEG revealed sharp waves in the

\footnotetext{
Received 19 May 1972.

* This work was aided by grants from John and Rosalind Redfern, The Pittsburgh Foundation (Charles A. Locke Educational and Charitable Trust), and the Pennsylvania Lions Sight Conservation and Eye Research Foundation, Inc.

Requests for reprints to T. S. Danowski, Department of Medicine, Magee-Womens Hospital, Pittsburgh, Pennsylvania 15213, USA.
}

left frontal area and right anterior temporal spiking. Audiometry demonstrated moderate bilateral perception deafness. Craniotomy performed at age 11 revealed arachnoiditis in the area of the optic chiasm with atrophy of both optic nerves.

At age 21, the patient was $167 \mathrm{~cm}$ tall and weighed $66.7 \mathrm{~kg}$. In addition to the primary optic atrophy, vertical nystagmus and rare microaneurysms were present. Knee and ankle tendon reflexes could not be obtained. His testis was $4 \mathrm{~cm}$ long on the right and $3.5 \mathrm{~cm}$ on the left.

Except for variable hyperglycaemia, blood and serum solutes have been normal. Glucose tolerance test revealed a clearly diabetic curve with no evidence of insulin response (Morgan, 1966) to an oral glucose load. A minor growth hormone (Morgan, 1966) peak was recorded at the 5th hour of this test. Plasma $11(\mathrm{OH})$ corticosteroid levels (Mattingly, 1962) have been within the normal range. Intravenous arginine $(0.41 \mathrm{mg} / \mathrm{kg})$ had no effect upon serum insulin levels but did produce a rise in serum growth hormone to $11 \mathrm{ng} / \mathrm{ml}$. Serum PBI (Danowski, Johnston, and Greenman, 1950) and thyroidal ${ }^{131}$ I uptake were $3.8 \gamma \%$ and $16 \%$, respectively. Creatinine clearance (Peters, 1942) was $141 \mathrm{ml} / \mathrm{min}$. The urinary 17-ketosteroids (Holtorff and Koch, 1940) were 12.2 with Porter-Silber chromogens (Porter and Silber, 1950) at 11.4 and compound $S$ metabolites (Henke, Doe, and Jacobson, 1960) at 0.88 mg/day.

Case 2. (brother of case 1). This 24-year old single male was found to have diabetes mellitus at the age of 3 years following polyuria, polyphagia, and polydipsia. He was treated with an anti-diabetic diet and insulin, most recently 54 units of NPH daily. At the age of 12 years, a diagnosis of optic atrophy was also made following the discovery of optic atrophy in his sibs. At age 15, urine volumes increased to $8 \mathrm{l} / \mathrm{dy}$. Twenty hours of water deprivation raised urine osmolarity relative to serum only slightly, ie, 455 versus 314 milliosmols, respectively, during an interval when urine sugar was zero. Chlorpropamide, $250 \mathrm{mg} / \mathrm{dy}$, reduced urine volumes to $2 \mathrm{l} / \mathrm{dy}$. The intravenous infusion of arginine $(0.41 \mathrm{mg} / \mathrm{kg})$ produced a rise in the serum growth hormone to $25 \mathrm{ng} / \mathrm{ml}$. 
Case 3. An 18-year-old male and 2nd cousin of Cases 1 and 2 on the maternal side. Diabetes mellitus was diagnosed at the age of 4 years on the basis of glycosuria and hyperglycaemia and treated with diet and insulin (current dosage: 55 units Lente and 10 units Semi-Lente). At the age of 16 years, blurring of vision led to the discovery of primary optic atrophy. Twentyfour hour urine volume was $2 \cdot 6$ litres.

Case 4. (The 15-year-old sister of case 3 and 2nd cousin of cases 1 and 2 on the maternal side). Diabetes mellitus was diagnosed at the age of 3 years following glycosuria and hyperglycaemia and treated with diet and insulin (current dosage: 95 Lente and 10 units SemiLente). At the age of 12 years examination of the eyes revealed primary optic atrophy and a slight decrease in visual acuity. Twenty-four hour urine volume was $3 \cdot 2$ litres.

The Pedigree of the new family presented here is shown in Fig. 1. Inheritance patterns in families previously reported (DeLawter, 1949; Fraccaro and

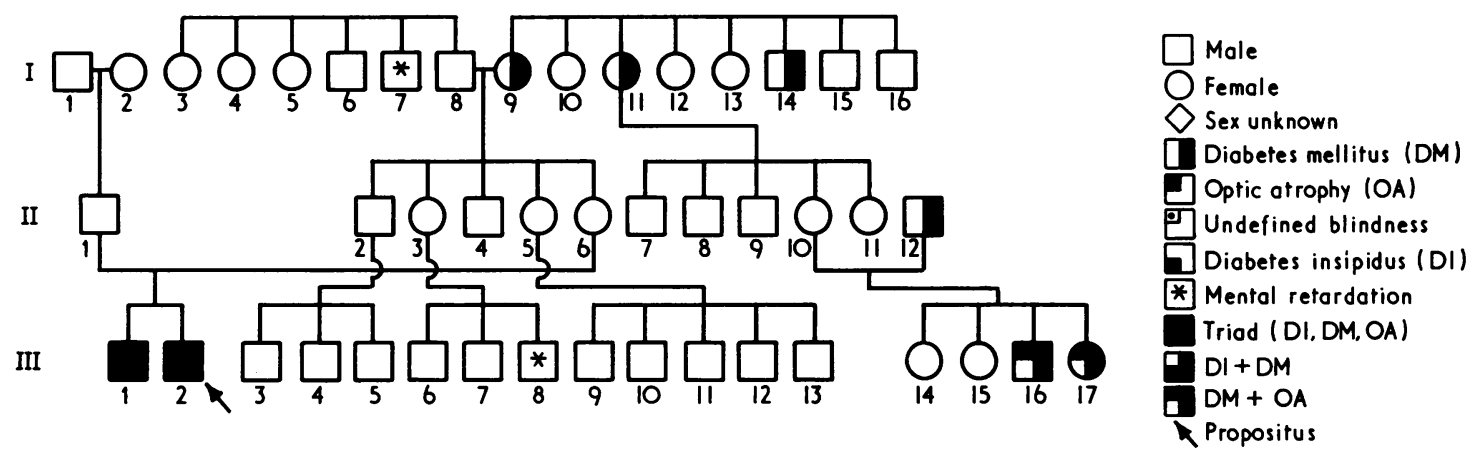

FIG. 1

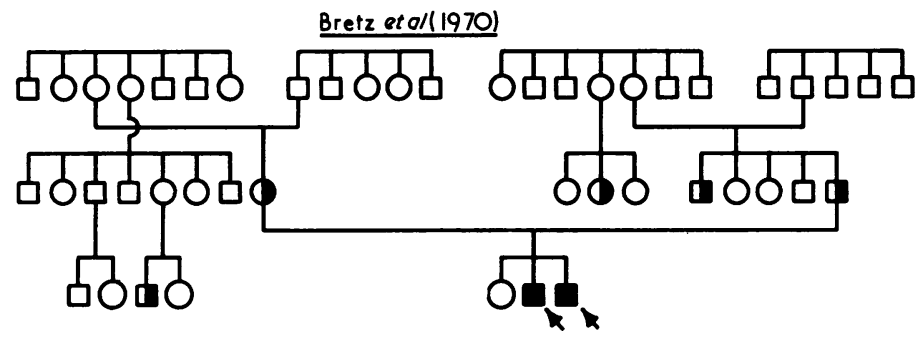

Raitietd (1963)
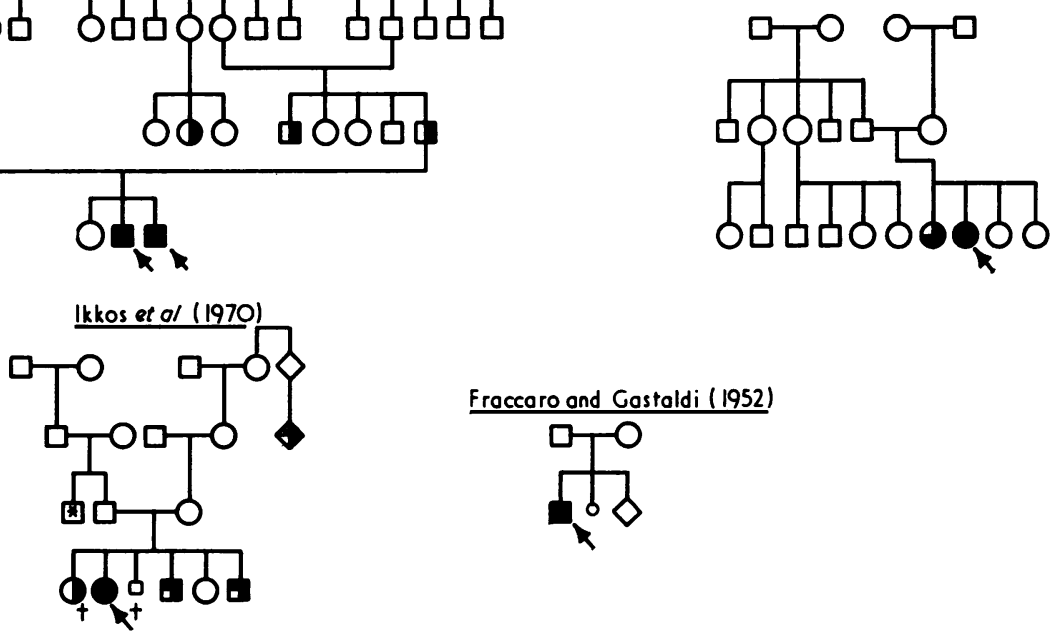

Froccaro and Gostaldi (1952)
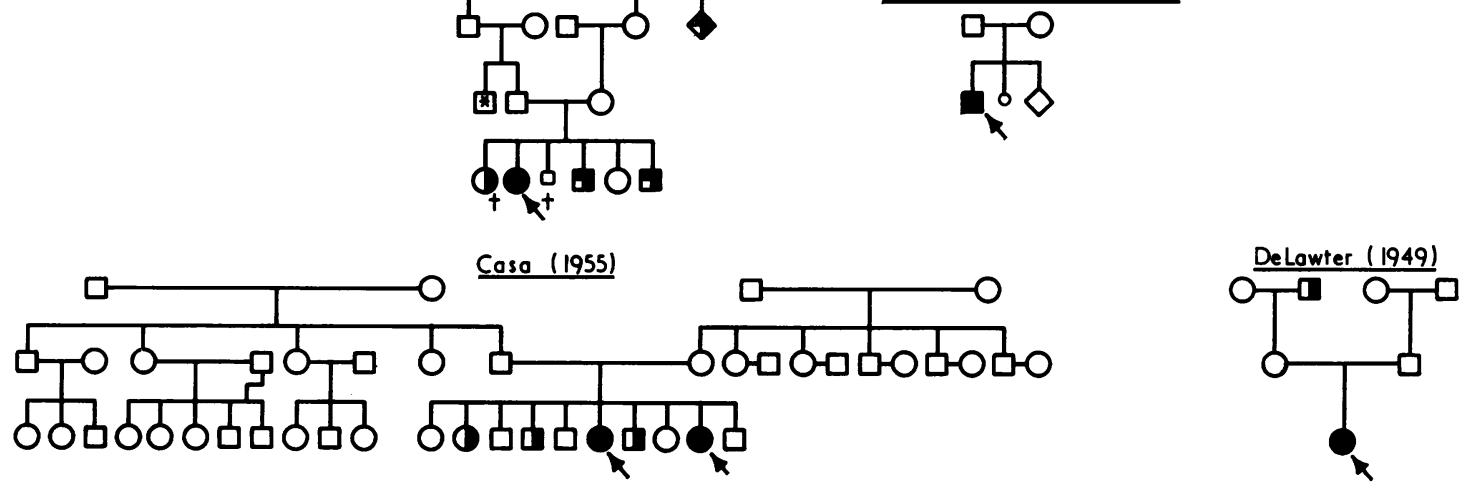

FIG. 2 
TABLE I

SUMMARY OF DIABETES INSIPIDUS (DI) DIABETES MELLITUS (DM), AND OPTIC ATROPHY (OA) IN SEVEN KINDREDS

\begin{tabular}{l|c|c}
\hline & $\begin{array}{c}\text { Total } \\
\text { Number }\end{array}$ & \multicolumn{1}{c}{ Reference(s) } \\
\hline $\mathrm{DI}+\mathrm{DM}+\mathrm{OA}$ & 10 & $\begin{array}{c}\text { DeLawter (1949); Fraccaro and } \\
\text { Gastaldi (1952); Casa (1955); } \\
\text { Raiti et al (1963); Bretz et al } \\
\text { (1970); Ikkos et al (1970); present } \\
\text { family }\end{array}$ \\
\hline $\mathrm{DI}+\mathrm{DM}$ & 1 & Casa (1955) \\
\hline $\mathrm{DM}+\mathrm{OA}$ & 4 & Ikkos et al (1970); present family \\
\hline $\mathrm{DM}$ only & 15 & $\begin{array}{c}\text { DeLawter (1949); Casa (1955); } \\
\text { Bretz et al (1970); Ikkos et al } \\
(1970) ; \text { present family }\end{array}$ \\
\hline $\mathrm{DI}+\mathrm{OA}$ & None & None \\
\hline $\mathrm{DI}$ only & None & \\
\hline $\mathrm{OA}$ only & \\
\hline
\end{tabular}

Gastaldi, 1952; Casa, 1955; Raiti et al, 1963; Bretz et al, 1970; Ikkos et al, 1970) are summarized in Fig. 2 and in Table I. Data from the 6 published pedigrees and the present one indicate that none of the traits, ie, diabetes insipidus (DI), diabetes mellitus (DM), or optical atrophy (OA), was inherited as a sex-linked or autosomal dominant trait. Indeed, the striking finding is that the DI-DM-OA combinations were invariably observed in propositii and in their sibs. Before the identification of the family described here, the manifestations had occurred in sibs of the same sex. In the 7 families cited in this report, only diabetes mellitus was reported in 15 individuals.

The data in Figs. 1 and 2 establish that neither diabetes insipidus nor optic atrophy occurred as an isolated trait. Moreover, DI was always associated with DM though DM did occur without DI, and OA was invariably accompanied by DM, ie, it was never seen in any individual as the sole manifestation of this triad of disorders or in combination with DI (Table I).

\section{Discussion}

This analysis is limited to the 7 pedigrees in each of which 3 disorders, viz, diabetes insipidus (DI), diabetes mellitus (DM), and primary optic atrophy (OA) have been manifest, though not always in one individual.

Diabetes insipidus is probably the most easily detected member of this grouping of DI-DM-OA, since excessive fluid intake and frequent voiding of urine are easily noted by family and non-family members. If this is so, it is reasonable to conclude that the diabetes insipidus component had appeared only among the propositii and has been absent from antecedent generations. This suggests that the diabetes insipidus in these 7 families is not a simple dominant trait (Blotner, 1951; Martin, 1959) and is not sex-linked (Forssman, 1945 and 1954). In a simple dominant type of inheritance, one expects to $\triangle$ find that one of the parents is affected and that the $\stackrel{\mathbb{P}}{\rightarrow}$ distribution of such affected parents between the $2 \overrightarrow{\vec{B}}$ sexes is about equal. Also, in a simple dominant type of inheritance in which only one parent is affected, an equal distribution of affected and nonaffected offspring is to be expected in the 2 sexes. Such distributions of DI were not evident in the 7 families and hence the DI in the DI-DM-OA कs complex does not appear to be a simple dominant $\overrightarrow{0}$ trait. Similarly, DI does not fit the criteria for a sex-linked trait. In a sex-linked dominant trait, affected females should have an affected male or female parent and affected males must have an affected female parent. With a sex-linked recessive trait, all affected females must have an affected male parent. However, affected males need not have an $\dot{\infty}$ affected parent. Scrutiny of the 7 pedigrees indi- 9 cates that these criteria for a sex-linked dominant or recessive DI trait have not been met.

Diabetes mellitus on the other hand has appeared 10 times as an isolated manifestation in antecedent generations in the 7 pedigrees. However, diabetes mellitus is a relatively frequent disorder which occurs far more often without DI and without OA than with them and hence is a marker of doubtfut value in tracing the genetic patterns of DI-DM-OA Among the manifestations of these 3 disorders in the 7 families, DI never occurred alone and, when it did occur, it was always associated with DM. The latter was true in all 11 instances of DI recorded in these 7 families. On the other hand, the fact that DM can occur without the DI in such families is documented 15 times in the 7 families and is presumably in keeping with the wide dispersion of $\mathrm{DM}$ as an isolated trait in various ethnic groups. The invariable occurrence of DM when DI was present suggests that this type of DM occurs secondary to this type of DI. In other words, a portion of the gene responsible for this type of DI produces a polypeptide chain which results in a phenocopy of diabetes mellitus. This would account for the invariable occurrence of $\mathrm{DM}$ whenever DI had developed.

Primary optic atrophy has not been reported among the parents, grandparents, and collateral relatives of propositii with the various combinations of DI-DM-OA. Admittedly, the identification of OA in earlier members of the kindred would be less likely than the identification of DI and DM and even marked diminution of vision in nonsenescent members might escape detection, but one can deal only with the fact that none of the antecedents of the propositus in the 7 families had OA. Findings

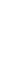

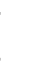


among the propositii and their sibs permit speculation as to whether $\mathrm{OA}$ is an independent genetic trait. OA has not appeared as an isolated manifestation amongst the propositii or their sibs in any of the 7 families. Granted that, compared to DI, $O A$ is not as readily detected clinically, one can still argue that in families stigmatized with DI-DM-OA and under medical observation, isolated manifestations of OA are more apt to be indentified. Furthermore, there have been no instances of DI and OA in combination in any of the families whereas DM and OA combinations have occurred 4 times. This record raises the possibility that $\mathrm{OA}$ is not an independent trait but is dependent upon and a sequel of DM. In other words, diabetes can be associated with or give rise to a variety of neuropathic and neurological changes, including OA (Rose et al, 1966; Waite and Beetham, 1935; Wolfram, 1938; von Noorden, 1939). Furthermore, these instances of OA do not appear to fall into the recognized hereditary forms of this disorder. Optic nerve changes which have been identified in the index cases in these 7 families and in other members of their generation appeared in the early years of life and hence do not represent Leber's hereditary optic atrophy, a recessive sex-linked trait of adult onset (Waardenburg, 1969). Furthermore, in the series of families described here, there were 6 affected females with normal parents, a finding which also excludes a recessive sex-linked trait. Also, infantile optic atrophy appears to be unlikely; the dominant type is excluded by the lack of affected parents or affected offspring and the congenital recessive type by the fact that it is fully developed by the age of 3 years (Francois, 1962).

In view of the fact that to date neither DI nor OA have appeared as independent traits or together in families with DI-DM-OA in various combinations, we wish to suggest the working hypothesis that genetically DI-DM-OA is but a single trait. Support for alternative genetic patterns such as 3 or 2 separate traits will require isolated instances of DI or of OA or of the 2 in combination unaccompanied by diabetes mellitus. If such instances do occur, then the view that DI-DM-OA is a manifestation of a single gene will of course no longer be tenable.

\section{Summary}

The frequency and associations of the diabetes insipidus, diabetes mellitus, optic atrophy (DIDM-OA) complex in propositii and their sibs are consonant with the hypothesis that the clinical manifestations result from a single genetic trait rather than from the independent inheritance of
3 traits. This hypothesis is based on the finding that in the 7 families described to date, DI has only been present with DM though DM has occurred without DI, neither OA nor DI has been reported as an isolated manifestation, and, finally, that combinations of only DI and OA have not been observed in such pedigrees. The above hypothesis presumes that $\mathrm{DM}$ is a component, ie, a fraction of the genetic trait for DI, and that OA also is not an independent genetic trait but a neurological sequel of DM. However, if isolated instances of DI or of OA or combinations of the two are eventually identified in kindreds with the DI-DM-OA complex, the hypothesis that this triad results from one pleiotropic gene would no longer be tenable.

\section{REFERENCES}

Blotner, H. (1951). Diabetes Insipidus. Oxford University Press, New York.

Bretz, G. W., Baghdassarian, A., Graber, J. D., Zacherle, B. J., Norum, R. A., and Blizzard, R. M. (1970). Coexistence of diabetes mellitus and insipidus and optic atrophy in two siblings. American fournal of Medicine, 48, 398-403.

Casa, C. (1955). Sul diabete giovanile misto famigliare. Acta Geneticae Medicae et Gemellologiae, 4, 230-241.

Danowski, T. S., Johnston, S. Y., and Greenman, J. H. (1950). Alterations in serum iodine fractions induced by the administration of inorganic iodide in massive dosage. Fournal of Clinical Endocrinology and Metabolism, 10, 519-531.

DeLawter, D. E. (1949). Coexistence of diabetes insipidus and diabetes mellitus. Medical Annals of the District of Columbia, 18, 398-400.

Forssman, H. (1945). On hereditary diabetes insipidus: with special regard to a sex-linked form. Acta Medica Scandinavica, Suppl. No. 159.

Forssman, H. D. (1954). Form of diabetes insipidus characterized by sex-linked inheritance and unresponsiveness to the antidiuretic hormone: new genotypic entity. Acta Endocrinologica, 16, 355364.

Fraccaro, M. and Gastaldi, F. (1952). La patologia della sindrome di Laurence-Moon-Biedl. Folia Hereditaria et Pathologica, 2, 177-214.

Francois, J. (1962). Progress in ophthalmic genetics. In Progress in Medical Genetics II, Chapter 9, ed. by A. G. Steinberg and A. Bearn. Grune and Stratton, New York and London.

Henke, W. J., Doe, R. P., and Jacobson, M. E. (1960). A test of pituitary reserve utilizing intravenous $S U-4885$, with a new method for extraction of 11-desoxycorticosteroids. Fournal of Endocrinology and Metabolism, 20, 1527-1531.

Hickey, R. C. and Hare, K. (1944). The renal excretion of chloride and water in diabetes insipidus. Fournal of Clinical Investigation, 23, 768-775.

Holtorff, A. F. and Koch, F. C. (1940). The colorimetric estimation of 17-ketosteroids and their application to urine extracts. Fournal of Biological Chemistry, 135, 377-392.

Ikkos, D. G., Fraser, G. R., Matsouki-Gavra, E., and Petrochilos, M. (1970). Association of juvenile diabetes mellitus, primary optic atrophy and perceptive hearing loss in three sibs, with additional idiopathic diabetes mellitus insipidus in one case. Acta Endocrinologica, 65, 95-102.

Martin, F. I. R. (1959). Familial diabetes insipidus. Quarterly fournal of Medicine, 28, 573-582.

Mattingly, D. (1962). A simple fluorimetric method for the estimation of free 11-hydroxycorticoids in human plasma. Fournal of Clinical Pathology, 15, 374-379.

Morgan, C. R. (1966). Immunoassay of human insulin and growth hormone simultaneously using I-131 and I-125 tracers. Proceedings of the Society for Experimental Biology and Medicine, 123, 230233.

Noorden, C. W. von (1939). Die Zuckerkrankheit und ihre Behandlung. Hirschwald, Berlin. 
Peters, J. H. (1942). Determination of creatinine and creatine in blood and urine with photoelectric colorimeter. fournal of Biological Chemistry, 146, 179-186.

Porter, C. C. and Silber, R. H. (1950). Quantitative color reaction for cortisone and related 17, 21-dihydroxy-20-ketosteroids. fournal of Biological Chemistry, 185, 201-207.

Raiti, S., Plotkin, S., and Newns, G. H. (1963). Diabetes mellitus and insipidus in two sisters. British Medical fournal, 2, 16251629.

Rose, C., Fraser, G. R., Friedmann, A. I., and Kohner, E. M. (1966). The association of juvenile diabetes mellitus and optic atrophy:
Clinical and genetical aspects. Quarterly fournal of Medicine, 35, 385-405.

Waardenburg, P. J. (1969). Some remarks on the clinical and genetic puzzle of Leber's optic neuritis. Fournal de Génétique Humaine, 17, 479-495.

Waite, J. H. and Beetham, W. P. (1935). The visual mechanism in diabetes mellitus (a comparative study of 2,002 diabetics and 457 non-diabetics for control). New England fournal of Medicine, 212, $367-379$; 429-443.

Wolfram, D. J. (1938). Diabetes mellitus and simple optic atrophy among siblings: report of four cases. Proceedings of the Staff Meetings of the Mayo Clinic, 13, 715-718.

\section{Forthcoming Symposia}

The Sheba International Symposium on Genetic Polymorphisms and Diseases in Human Populations will be held at the Tel-Aviv University from 18-22 March 1973. Additional information may be obtained from: Professor B. Ramot MD, The Chaim Sheba Medical Centre, Tel-Hashomer, Israel.

A Symposium on Drugs and the Unborn Child will be held at thc Commodore Hotel, New York City on 15-16 March 1973. Sponsored by the National Foundation-March of Dimes, the symposium programme will be presented by Cornell University Medical College.

Further information may be obtained from the Department of Pediatrics, Cornell University Medical College, 1300 York Avenue, New York NY 10021, USA. 